\title{
Microstructure and Magnetic Properties of Selected Laser Melted Ni-Mn-Ga and Ni-Mn-Ga-Fe Powders Derived from as Melt-Spun Ribbons Precursors
}

\author{
Wojciech Maziarz ${ }^{1}$, Paweł Czaja ${ }^{1, *}$, Robert Chulist ${ }^{1}$, Anna Wójcik ${ }^{1}$, Łukasz Żrodowski ${ }^{2}$, Bartosz Morończyk ${ }^{2}{ }^{\circledR}$, \\ Rafał Wróblewski ${ }^{2}$ and Maciej Kowalczyk ${ }^{2}$ \\ 1 The Aleksander Krupkowski Institute of Metallurgy and Materials Science Polish Academy of Sciences, \\ 25 Reymonta St., 30-059 Kraków, Poland; w.maziarz@imim.pl (W.M.); r.chulist@imim.pl (R.C.); \\ a.wojcik@imim.pl (A.W.) \\ 2 The Faculty of Materials Science and Engineering, Warsaw University of Technology, 141 Wołoska St., \\ 02-507 Warsaw, Poland; lukasz.zrodowski.dokt@pw.edu.pl (Ł.Ż.); bartosz.moronczyk.dokt@pw.edu.pl (B.M.); \\ rafal.wroblewski@pw.edu.pl (R.W.); maciej.kowalczyk@pw.edu.pl (M.K.) \\ * Correspondence: p.czaja@imim.pl
}

\section{check for}

updates

Citation: Maziarz, W.; Czaja, P.; Chulist, R.; Wójcik, A.; Żrodowski, Ł.; Morończyk, B.; Wróblewski, R.; Kowalczyk, M. Microstructure and Magnetic Properties of Selected Laser Melted Ni-Mn-Ga and Ni-Mn-Ga-Fe Powders Derived from as Melt-Spun Ribbons Precursors. Metals 2021, 11, 903. https://doi.org/10.3390/ met11060903

Academic Editor: Paolo Ferro

Received: 31 March 2021

Accepted: 28 May 2021

Published: 31 May 2021

Publisher's Note: MDPI stays neutral with regard to jurisdictional claims in published maps and institutional affiliations.

Copyright: (c) 2021 by the authors. Licensee MDPI, Basel, Switzerland. This article is an open access article distributed under the terms and conditions of the Creative Commons Attribution (CC BY) license (https:/ / creativecommons.org/licenses/by/ $4.0 /)$.
Abstract: Selective Laser Melting was successfully used as a fabrication method to produce Ni-MnGa and Ni-Mn-Ga-Fe ferromagnetic shape memory alloys. The starting material in a powder form with an average particle size of about $17.6 \mu \mathrm{m}$ was produced by milling of as melt-spun ribbons. The microstructure, phase composition, and martensitic transformation behavior of both powder precursors and laser melted alloys were investigated by several methods, including high energy X-ray diffraction, electron microscopy, and vibrating sample magnetometry. The as laser melted materials are chemically homogenous and show a typical layered microstructure. Both alloy compositions have a duplex structure consisting either of austenite and 10M martensite (Ni-Mn-Ga) or a mixture of $14 \mathrm{M}$ and NM martensitic phases (Ni-Mn-Ga-Fe), contrary to the as milled powder precursors showing $f c c$ structure in both cases. The forward martensitic transformation takes place at 336 and $325 \mathrm{~K}$ for Ni-Mn-Ga and Ni-Mn-Ga-Fe, respectively, while the magnetic response is much stronger for Ni-Mn-Ga than for the quaternary alloy. The results show that Selective Laser Melting allows for producing of good quality, homogenous materials. However, their microstructural features and consequently shape memory behavior should be tailored by additional heat treatment.

Keywords: Ni-Mn-Ga; selective laser melting; microstructure; additive manufacturing

\section{Introduction}

Ferromagnetic Ni-Mn-Ga shape memory alloys capable of $12 \%$ magnetic field induced strain, high-frequency response $(\mathrm{kHz})$, and extended fatigue lifetime $\left(\sim 2 \times 10^{9}\right.$ cycles $)$ were widely studied in the past two decades as promising candidates for smart materials devices [1,2]. Most often, they come in a form of single crystals, and as such, free of any grain boundary constraint, they can offer up to the maximum allowable strain. However, more recently, semi-constrained polycrystalline Ni-Mn-Ga alloys, produced as foams, have been shown to yield up to $8.7 \%$ recoverable strain [3], which has subsequently triggered vivid research interest in the development of alternative synthesis routes for Ni-Mn-Ga alloys. This interest is increased by prospects of a less time-consuming and more predefined geometry-specific manufacturing approach as opposed to single crystal growth. In this light, additive manufacturing has come forth with its high potential [4-22].

There are various ways of 3D printing, but most of them rely fundamentally on fine powder precursor feedstock [23-26]. For producing such fine powder, one may again turn to a number of different techniques, but the common pre-requirement that a good quality powder has to meet is ideally a spherical shape of particles, uniform particle size distribution, and homogeneity-if starting from a pre-alloyed source. In 
terms of preserving the starting composition, vital for the highly composition sensitive functional performance of Ni-Mn-Ga alloys, melt spinning technique has been frequently highlighted as a viable option. Its major advantage, apart from ensuring homogeneity, is scalability and intrinsic brittleness of resulting as melt spun Ni-Mn-Ga ribbons. Owing to that, brittleness melt-spun ribbons can be further easily pulverized to a predefined particle size before final loading onto a 3D printer. One has to bear in mind though, that heavy pulverization, although improving powder size and particle shape uniformity, can simultaneously severely degrade the structure, stabilize the martensite phase, or even suppress martensitic transformation $[27,28]$. Such radical structure interference would then entail careful optimization of 3D printing regime and application of additional heating stage for homogenization and structure recovery [26]. In this work, we, therefore, examine the evolution of microstructure and magnetic properties in as milled, as milled and annealed and selected laser melted Ni-Mn-Ga and Ni-Mn-Ga-Fe powders originating in as melt spun ribbons. Microstructure and magnetic response of the powders following different thermomechanical histories are compared. It is demonstrated that through 3D printing, some functional behavior of Ni-Mn-Ga and Ni-Mn-Ga-Fe is restored, but additional heat treatment is unavoidable for maximizing the ultimate response.

\section{Materials and Methods}

$\mathrm{Ni}_{50.2} \mathrm{Mn}_{28.3} \mathrm{Ga}_{21.5}$ and $\mathrm{Ni}_{50} \mathrm{Mn}_{25} \mathrm{Ga}_{20} \mathrm{Fe}_{5}$ powders were produced by mechanical milling of melt-spun ribbons in a vibration mill (Fritsch PULVERISETTE 0) with 1 ball $50 \mathrm{~mm}$ in diameter and under $0.5 \mathrm{~mm}$ vibration amplitude for $8 \mathrm{~h}$. The ball powder ratio was 95:1. Small amounts of each powder were separately heat-treated at $1170 \mathrm{~K}$ for $1 \mathrm{~h}$ in an argon atmosphere. Subsequently, powders were used for 3D printing employing Selective Laser Melting (SLM) technique using the ReaLizer 50 with laser beam of $120 \mathrm{~W}$ and $1064 \mathrm{~nm}$ wavelength. The scanning parameters were as follows: beam power $37.5 \mathrm{~W}$, beam speed $250 \mathrm{~mm} / \mathrm{s}$, and line spacing $50 \mu \mathrm{m}$. Samples were created via single line melting. There were two types of melting strategies implemented: laser patch along the plate direction $(\mathrm{N})$ and laser patch oscillating with $100 \mathrm{um}$ amplitude $(\mathrm{O})$. There was no rotation involved. Layer thickness was $25 \mathrm{um}$. Build plate was AISI 304 steel. As a result, samples having $6 \mathrm{~mm}$ in length, $3 \mathrm{~mm}$ in width, and thickness of about $500 \mu \mathrm{m}$ were produced.

Microstructure and structure of the samples were studied using FEI-SEM XL30 scanning electron microscope (SEM) equipped with an X-ray energy dispersive spectrometry (EDS) analyzer, dual beam high-resolution Scanning Electron Microscopy FEI Quanta FEG SEM integrated with the EDAX Trident system (Apollo 40 EDS spectrometer, TEXS WDXS spectrometer, and Hikari EBSD camera) and Tecnai G2 (200 kV) transmission electron microscope (TEM) fitted with an Energy Dispersive X-ray (EDX) microanalyzer coupled with a High Angle Annular Dark Field Detector (HAADF). Powder samples for TEM observations were prepared by placing a small amount of powder particles on the $3 \mathrm{~mm}$ diameter copper grid with the amorphous carbon thin film. For the preparation of thin foil from printed alloys, electro-polishing with TenuPol-5 double jet electropolisher (electrolyte of nitric acid (1/3) and methanol (2/3)) at temperature $\sim 240 \mathrm{~K}$ was applied. For EBSD 3D printed alloys', the surface was mechanically polished and then electropolished using an electrolyte of perchloric acid (1/5) and ethanol (4/5) at ambient temperature. Structure evolution was further elaborated by $\mathrm{X}$-ray diffraction employing high-energy synchrotron radiation $(87.1 \mathrm{keV})$ and a 2-dimensional detector at a distance of $1230 \mathrm{~mm}$ at HZG materials science beamline P07B at DESY in Hamburg, Germany. Mass magnetic susceptibility and magnetization were measured using the vibrating sample magnetometer (VSM) option of the Quantum Design Physical Property Measurement System (PPMS-9) between $5 \mathrm{~K}$ and $380 \mathrm{~K}$ temperature and under a magnetic field of $50 \mathrm{mT}$ (and $5 \mathrm{~T}$ ). 


\section{Results and Discussion}

Particle shape and size distribution of the initial powder source is illustrated through the exemplary Ni-Mn-Ga powder (Figure 1a); the results for the Ni-Mn-Ga-Fe powders were similar and thus are not shown. Powder characteristics were evaluated from SEM image analysis (Figure 1a). It has been found that particles exhibit a typical coarse morphology, and their mean size, estimated based on normal asymmetric size distribution, was $17.3 \mu \mathrm{m}$ (Figure $1 \mathrm{~b}$ ). The highest frequency of particle sizes was in the range of 1-25 $\mu \mathrm{m}$, while a small amount of particles was above $40 \mu \mathrm{m}$ (Figure 1b). A fraction of particles with rounded edges and a size of about $0.5 \mu \mathrm{m}$ was also noted. For detailed structural examination, TEM was applied (Figure 2). The TEM studied particles had ca. $0.5 \mu \mathrm{m}$ in diameter (Figure 2a) and the corresponding SAED pattern (Figure 2c) indicated that particles possessed a nanocrystalline $f c c$ structure. The size of crystallites measured in the dark field image-DF (Figure 2b) performed from the (111) $f c c$ planes was in the range of 5 to $20 \mathrm{~nm}$. Regardless of the size and shape, the particles have a high chemical homogeneity, which was confirmed by the EDS analyses made in the area marked by a black square frame (Figure 2d). The average chemical composition is $\mathrm{Ni}_{50.3 \pm 0.5} \mathrm{Mn}_{28.0 \pm 0.8} \mathrm{Ga}_{21.7 \pm 0.6}$, and it was very close to the nominal alloy composition. After annealing (Figure 3), crystallite size, measured in DF on the (220) L2 1 planes (Figure 3b), was larger than $100 \mathrm{~nm}$ and crystallites show a characteristic contrast close to the banded microstructure. It can then be assumed that there was some martensite in the annealed powder sample. The structure of particles changed from $f c c$ to the $\mathrm{L} 22_{1}$ (Figure $3 c$ ), pointing to a phase transformation from $f c c$ to the L2 ${ }_{1}$ Heusler phase. Similar to the case of as milled powders without heat treatment, the chemical composition in annealed powders was close to nominal.
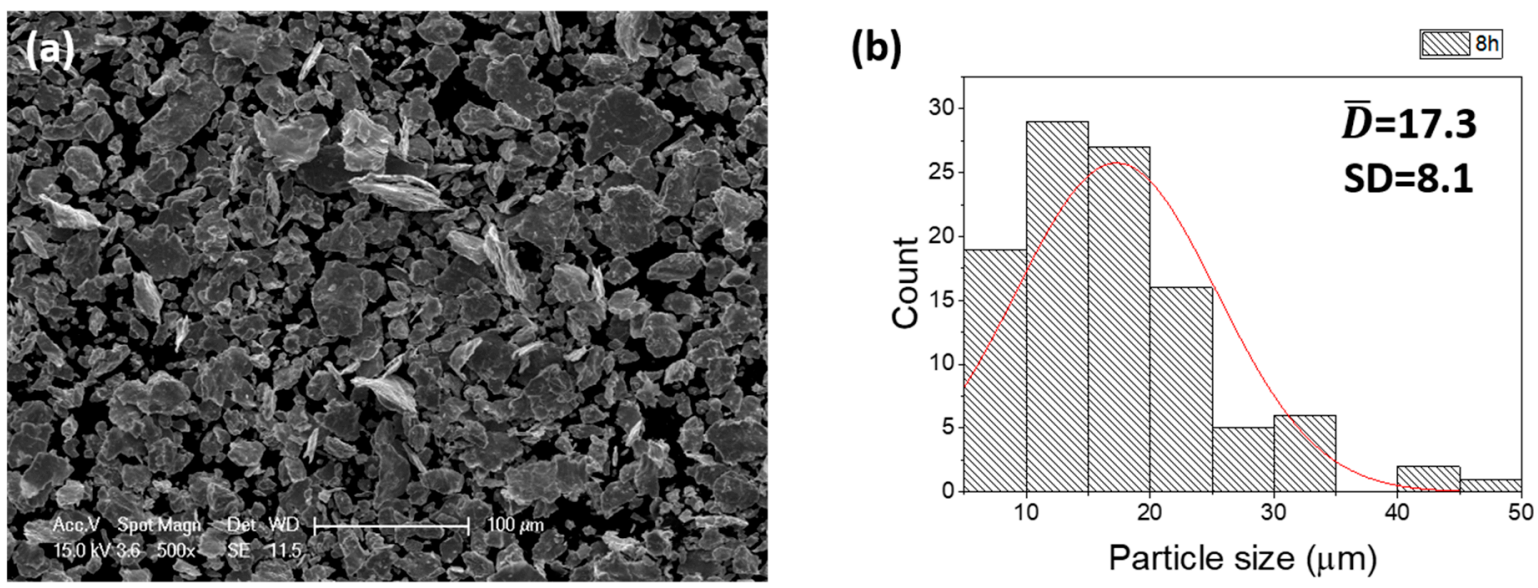

Figure 1. SEM image of powder resulting from $8 \mathrm{~h}$ of milling (a) and corresponding histogram illustrating particle size distribution (b).

Phase compositions of as milled, as milled and annealed and selected laser melted Ni$\mathrm{Mn}-\mathrm{Ga}$ and Ni-Mn-Ga-Fe powders were further examined with high-energy synchrotron radiation (Figure 4). The crystal structure of both as milled powders was virtually the same and it was determined to be the $f c c$ structure. The diffraction patterns obtained for the as laser melted Ni-Mn-Ga alloy revealed a duplex structure well indexable according to the coexisting $\mathrm{L} 2{ }_{1}$ austenite and $10 \mathrm{M}$ modulated martensite structures, whereas the Ni-MnGa-Fe laser melted powder developed a mixture of modulated $14 \mathrm{M}$ and non-modulated (NM) structures (Figure 4). Similar phase composition was found with powders annealed for $1 \mathrm{~h}$ at $1173 \mathrm{~K}$. Besides the qualitative comparison, a good quantitative agreement using Rietveld refinement was also obtained. In NiMnGa alloys, a volume fraction of about $63 \%$ of $10 \mathrm{M}$ martensite was found in the annealed state, while the amount of $10 \mathrm{M}$ martensite in the 3D printed sample was close to $55 \%$. These values for NiMnGaFe alloys and $14 \mathrm{M}$ martensite reach $95.5 \%$ in the annealed state, and about $88 \%$ in as laser melted one. This 
disparity in the amount of martensite fraction implies at least two technical issues. On the one hand, laser melting had no inhibitory influence on martensitic transformation, and on the other hand, a further annealing process was required to fully restore the $10 \mathrm{M}$ or $14 \mathrm{M}$ single-phase structure in selected laser melted samples.
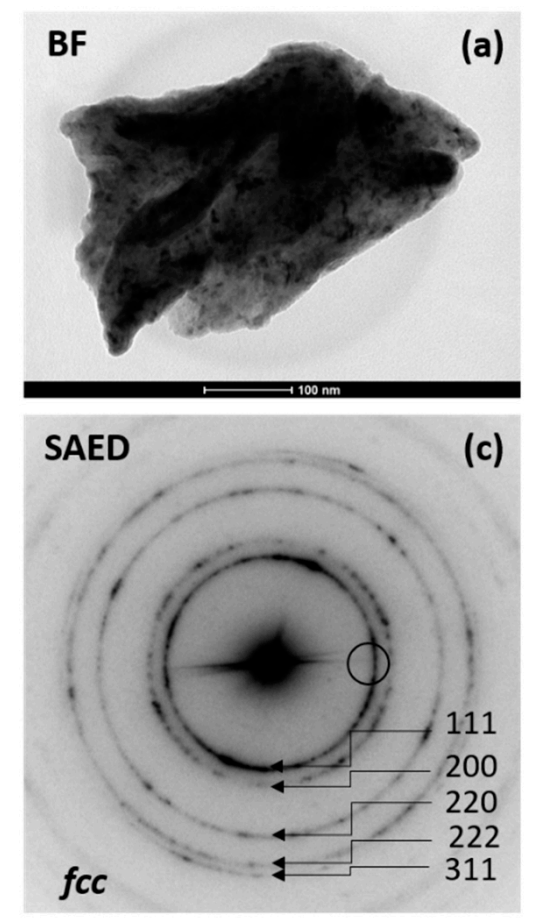
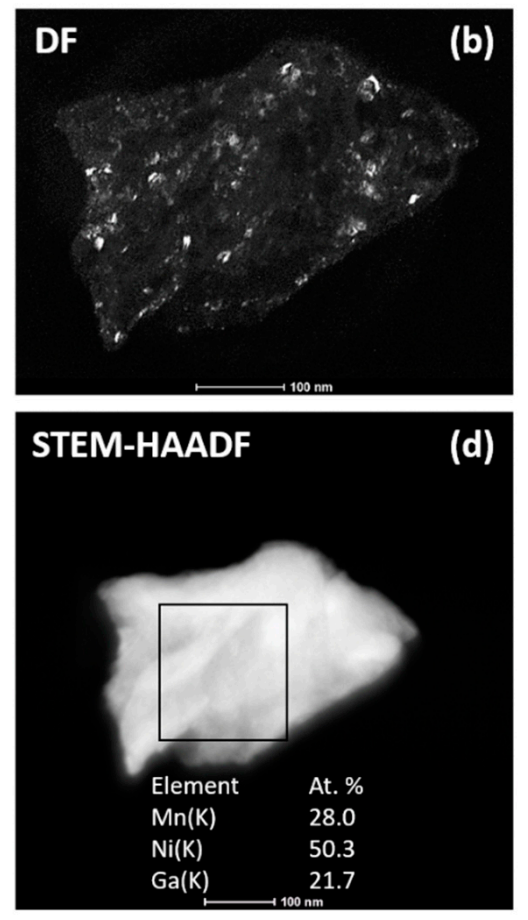

Figure 2. TEM bright field (a), dark field (b), selected area electron diffraction (c), and STEM-HAADF (d) images taken at room temperature from the powders after $8 \mathrm{~h}$ milling.
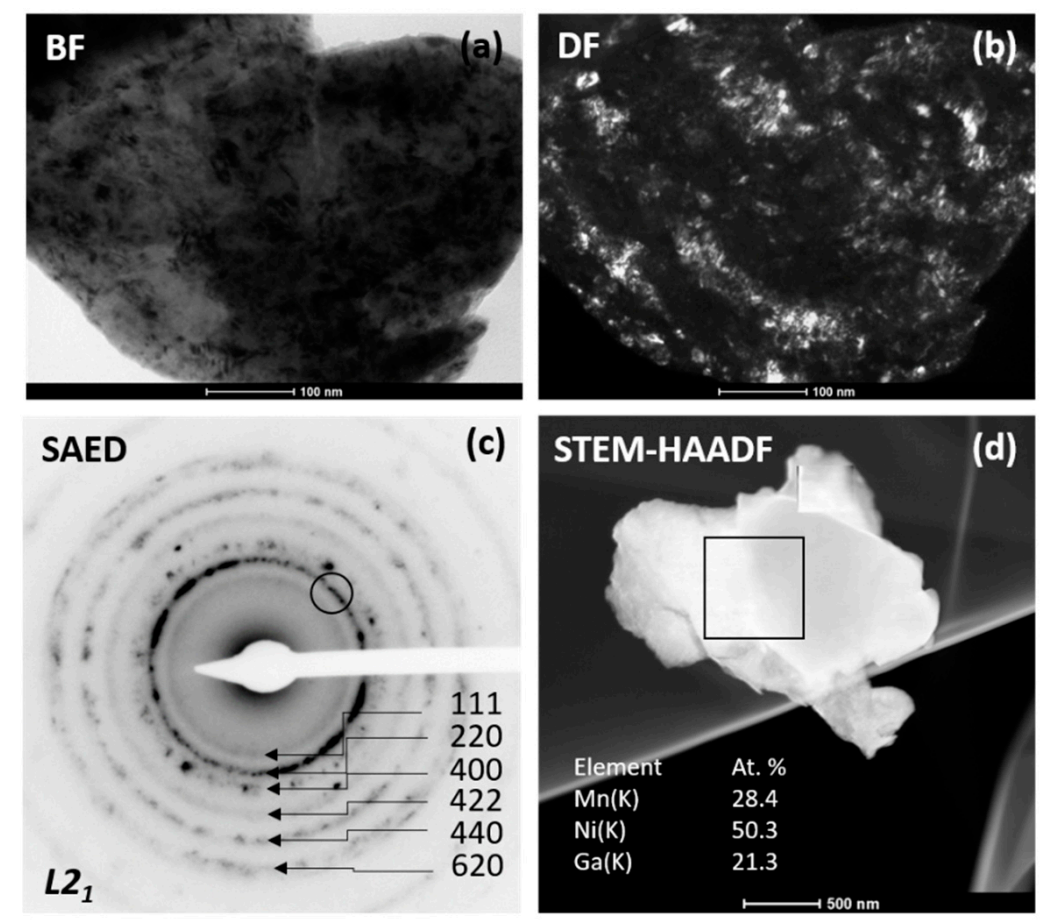

Figure 3. TEM bright field (a), dark field (b), selected area electron diffraction (c), and STEM-HAADF (d) images taken at room temperature from the powders after $8 \mathrm{~h}$ milling and annealing at $1173 \mathrm{~K}$ for $1 \mathrm{~h}$. 

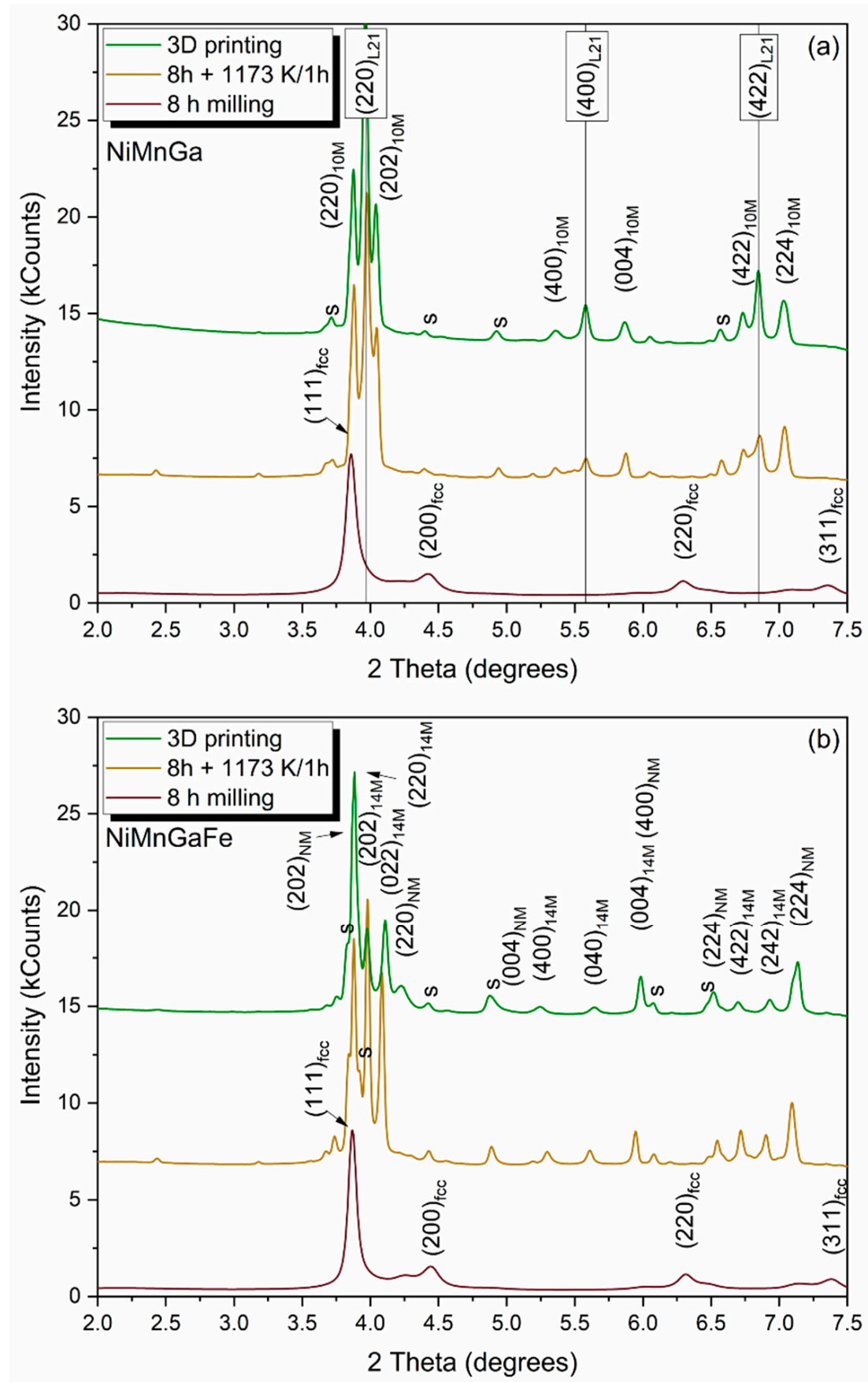

Figure 4. High energy synchrotron radiation diffraction patterns for as milled, milled and annealed and as printed Ni-Mn-Ga (a) and Ni-Mn-Ga-Fe (b) powders. The symbol "s" denotes satellite reflections related to modulations in martensite.

Morphologically the microstructure, inspected with scanning electron microscopy in a backscatter mode (SEM/BSE) (Figure 5), had a striped-like appearance, typical for 3D printed materials. It encompasses martensitic plates with subplate, fine twin-microstructure in consistence with XRD (Figure 4). In terms of chemical composition, there were no variations, what was confirmed from EDS analysis, and overall the chemical composition was coherent with the nominal composition, what deserves mention when taking into account the compositional complexity of the powders and volatility of $\mathrm{Mn}$. For more in-depth scrutiny of martensitic microstructure, an electron backscatter diffraction (EBSD) was applied (Figure 6). The EBSD also confirmed striped microstructure and a large density of twin boundaries associated with the 10M martensite [29]. It appears that 
each layer was composed of a single austenite orientation that grows within a particular layer. However, they show different twin configurations constituting distinct variant colonies. In addition, some faint lines observed may be related to intense epitaxial grow effects or recrystallization of neighboring stripes occurring during the material production. Interestingly, the microstructures in Figure 6 were dominated by $10 \mathrm{M}$ martensite, which was not fully consistent with X-ray volume fraction calculations. It appears that these regions undergo martensitic transformation because they are less defected and thereby more easily indexed by EBSD system. Even though they were less representative, they were selected for EBSD measurements in order to reveal twin configurations. However, for proper phase indication, synchrotron measurements were used.

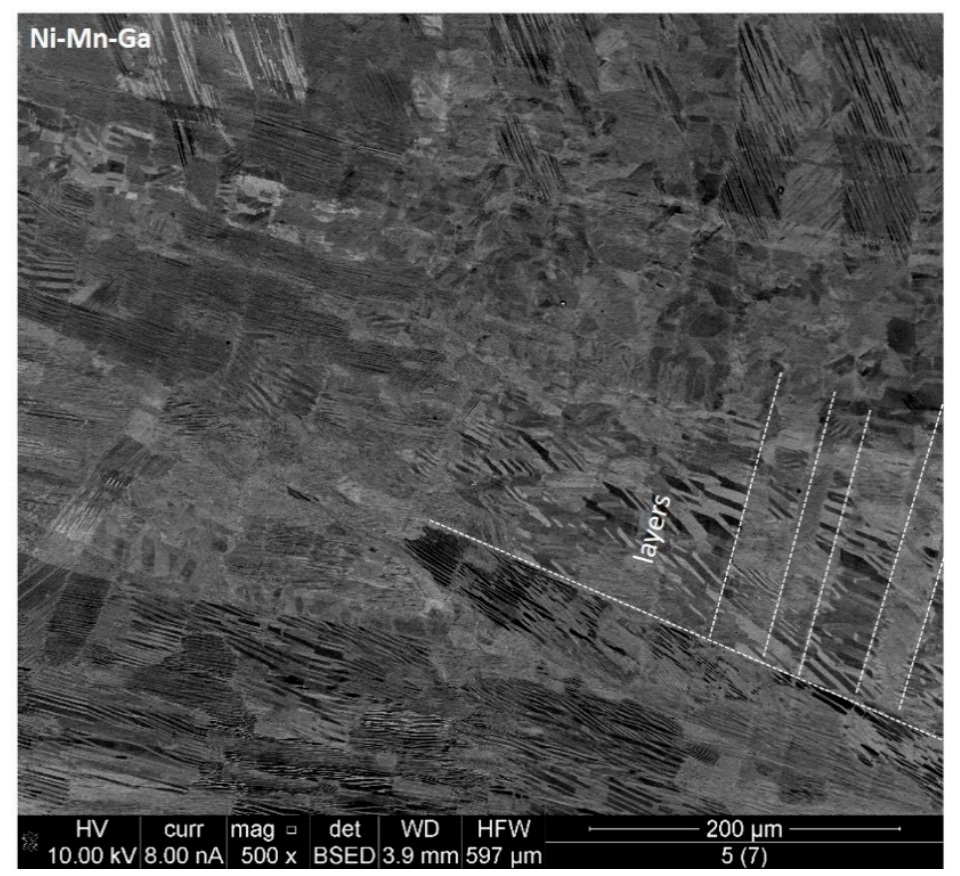

Figure 5. Backscatter electron (BSE) images of as laser melted Ni-Mn-Ga powders.
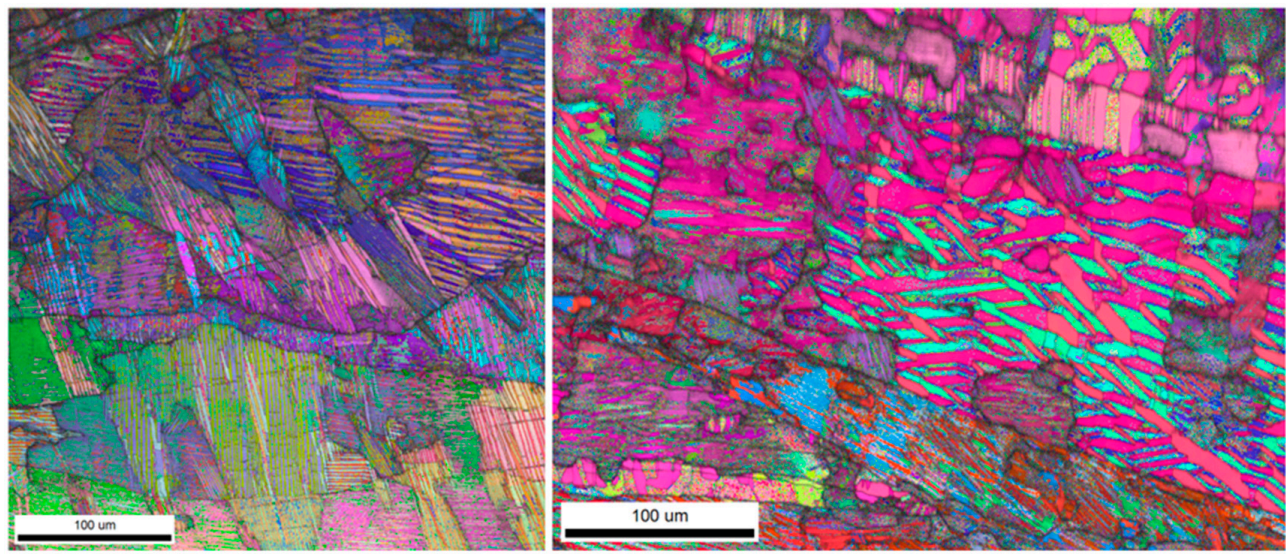

\section{Martensite}

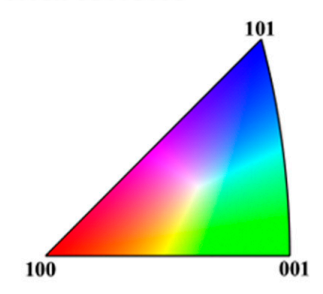

Figure 6. Electron backscatter diffraction (EBSD) images of as laser melted Ni-Mn-Ga powder.

Furthermore, detailed microstructural examination of as 3D printed alloys was conducted with TEM. Scanning Transmission STEM-HAADF (Figure 7) also confirms plate-like microstructure typical for the martensite phase. The average plate thickness was circa $150 \mathrm{~nm}$. Inside the macroplates, finer microscopic features were found, among them a high density of stacking faults or modulations. It was interesting to note two groups of variants belonging to two different colonies with orientation perpendicular to one another 
(Figure 7a). Both groups of variants differed morphologically, which may indicate that rather than from self-accommodation, their arrangement results from a layer by layer melting process. In terms of chemical composition in consistence with SEM/EDS there were no transparent fluctuations in the distribution of chemical elements, and the average composition for the two starting alloys was in agreement with nominal composition, and it was in the range $\mathrm{Ni}(48-51$ at.\%), Mn (23-25 at.\%), Ga (18-19 at.\%), and (Fe 6-8 at.\%) (Figure $7 \mathrm{~b}, \mathrm{c}$ ). A part from the martensitic plates, the microstructure contained a fair number of circular spots with dark contrast in HAADF-STEM. Their size oscillated around $100 \mathrm{~nm}$. The EDS chemical composition analysis confirmed that they were primarily composed of $\mathrm{Mn}$ and $\mathrm{O}$, which suggests that these spots may be associated with manganese oxides frequently encountered in Heusler based Ni-Mn alloys following thermal treatment under no protective atmosphere. Plate morphology was also well visible from bright field images (Figures 8 and 9), demonstrating distinct zones, one populated with martensitic plates and the other free of any plates. In general, two types of plates can be distinguished. One type has defined plate boundaries, most likely twin boundaries, and a high density of stacking faults or modulations. The second type has more diffused boundaries with a high density of dislocations. It can thus be assumed that in terms of morphology, the resulting as printed materials were inhomogeneous, which was related to heat distribution and occurrence of individual melting zones during the printing process.
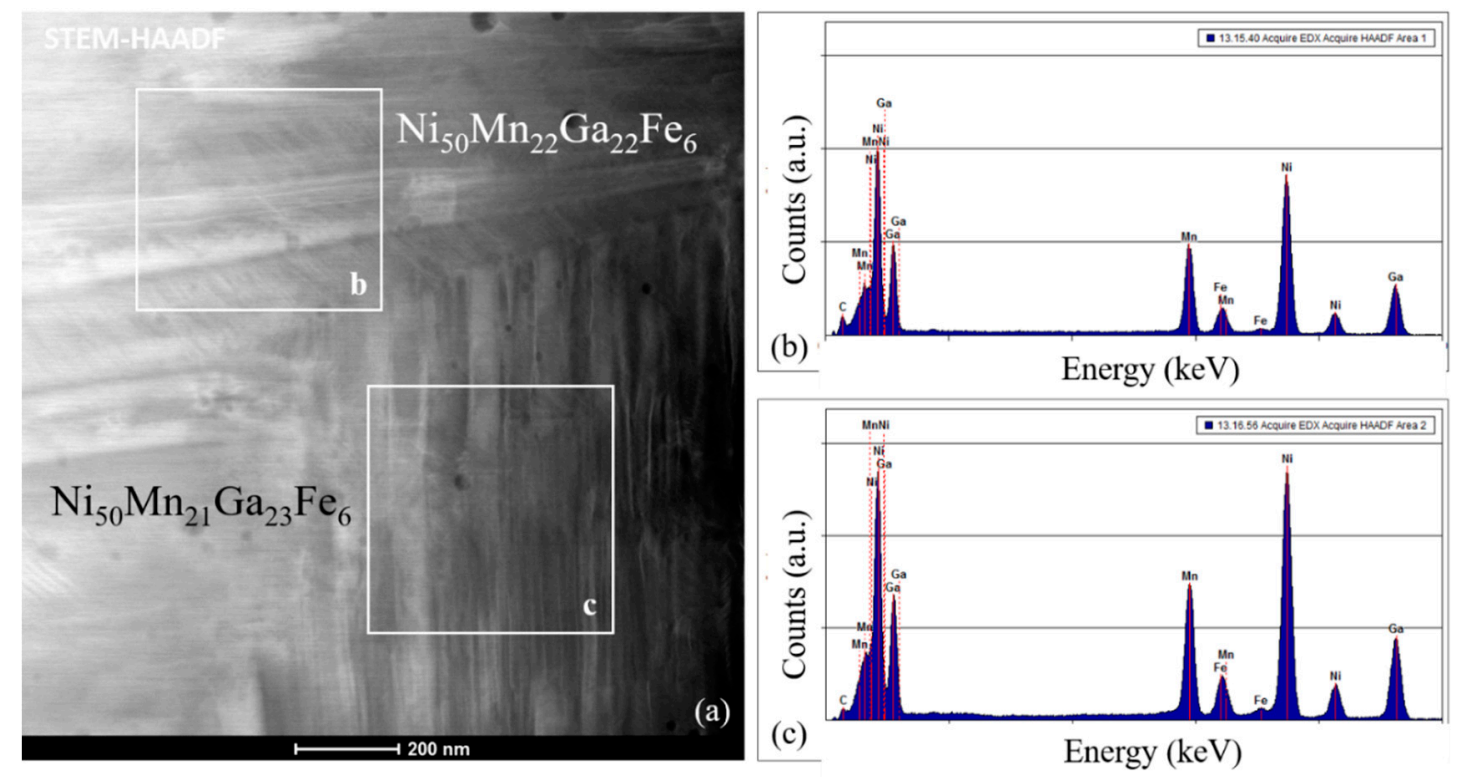

Figure 7. Scanning transmission electron microscopy image (a) and energy dispersive spectra from areas (b,c) corresponding to area marked with rectangle in (a) of as laser melted Ni-Mn-Ga-Fe powder.

Figures 8 and 9 collect a number of BF images and the corresponding selected area electron diffraction patterns (SAED). The SAED in Figure 8 can be well indexed according to the $\mathrm{L} 21$ austenite structure along the [001] zone axis. Interestingly this SAED shows diffuse streaking, indicated by arrows and originating from (202) planes, which were often found with premartensitic phenomena. The SAED in Figure 9, on the other hand, can be well indexed according to the $14 \mathrm{M}$ modulated martensite structure, which was given away by six satellite diffraction spots and the $91.5^{\circ}$ angle between (202) planes, indicating monoclinic symmetry. It slightly deviates from the value obtained for the $14 \mathrm{M}$ single crystals $\left(93.1^{\circ}\right)$, indicating the presence of NM phase and the fact that $14 \mathrm{M}$ martensite was not fully developed. However, this type of structure prevails in plates with well-defined boundaries. For a closer inspection of the atomic arrangement, High Resolution Electron Microscopy (HREM) was applied, and a few of the obtained images are shown in Figure 10 together with the corresponding Fast Fourier Transform (FFT) and inverse FFT. From the 
HREM image in Figure 10, one can notice an interface between austenite and martensite. The FFTs taken from the marked areas (white rectangle in Figure 10), as well as from the overall area, confirm a large number of microstructural faults within the studied area. Most prominent of these faults are plane discontinuities and plane bending witnessed for martensite structure. A typical tweed microstructure attributed to pre-martensitic phenomena is also well visible from Figure 10 in agreement with satellite streaking noted in Figure 8.
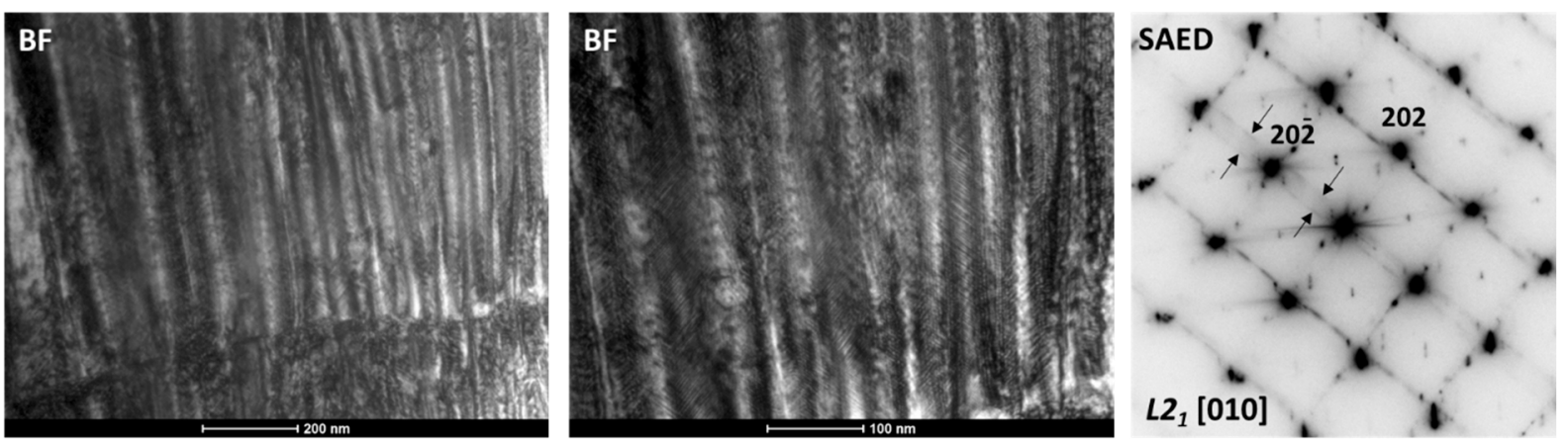

Figure 8. Bright field (BF) and the corresponding selected area electron diffraction (SAED) of as laser melted Ni-Mn-Ga-Fe powder taken from an area dominated with the $\mathrm{L} 2{ }_{1}$ austenite phase.
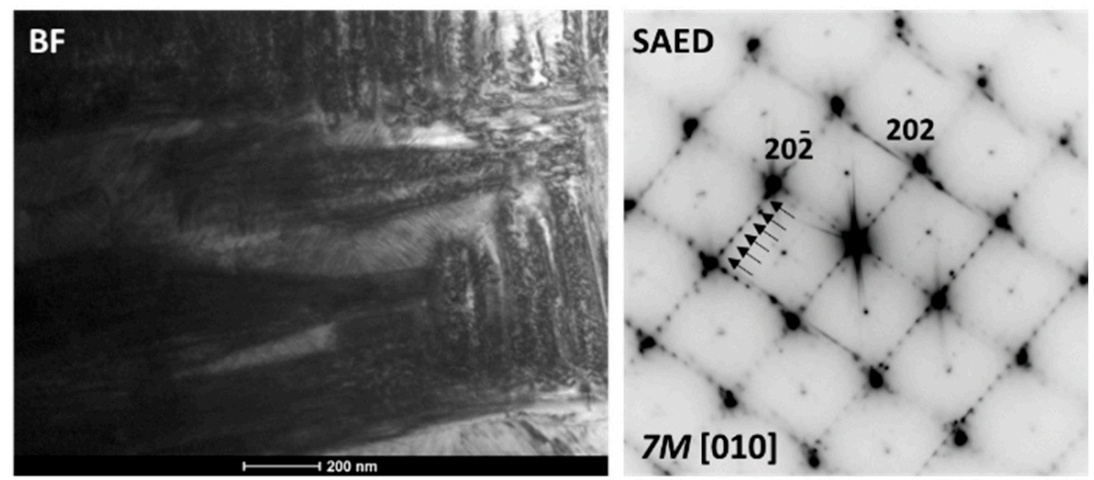

Figure 9. Bright field (BF) and the corresponding selected area electron diffraction (SAED) of as laser melted Ni-Mn-Ga-Fe powder taken from an area dominated with the 7M martensite phase.
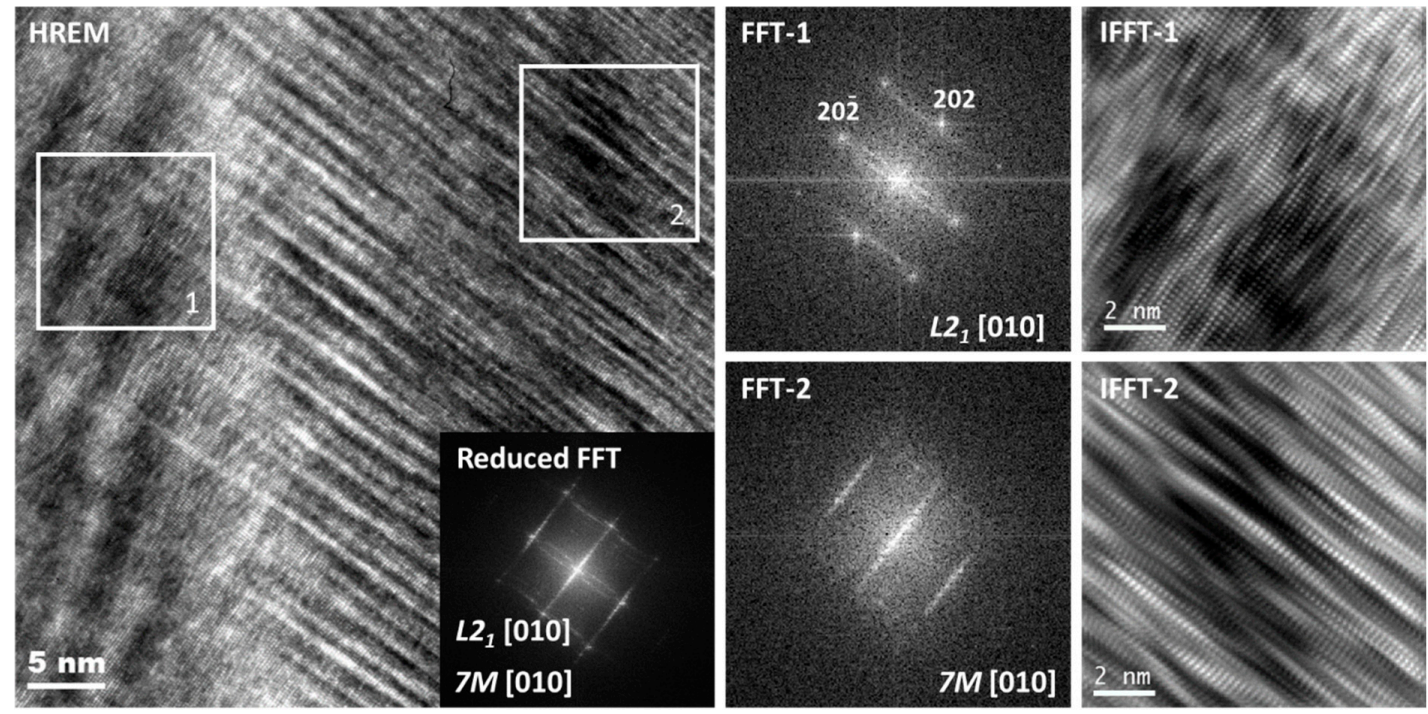

Figure 10. High resolution electron microscopy (HREM) images of as laser melted Ni-Mn-Ga-Fe powder. 
The thermomagnetic measurements for the starting as milled and milled and annealed as well as 3D printed Ni-Mn-Ga and Ni-Mn-Ga-Fe alloys are shown in Figure 11. The magnetic susceptibility and detailed magnetization response of as milled powders were evaluated elsewhere [29], it only needs to be remarked that milling suppresses martensitic transformation, and secondary annealing was required for its restoration. Irrespective of the powders, the magnetic susceptibilities versus temperature for the as laser melted Ni-Mn-Ga and Ni-Mn-Ga-Fe alloys are shown in Figure 11a. In consistence with the microstructural examination, the appearance of martensitic transformation was well recognisable from the hysteretic splitting between the field cooling and field heating curves, indicated with arrows in the Figure 11a. The Curie temperature inferred from the inflection point on the field cooling curve for the Ni-Mn-Ga alloys was $350 \mathrm{~K}$, the forward transformation took place at $336 \mathrm{~K}$, while the reverse transformation deducted from the field heating curve occurred at $339 \mathrm{~K}$. The forward and reverse martensitic transformation temperature difference indicated a small hysteresis on the order of $3 \mathrm{~K}$. The Curie temperature for the Ni-Mn-GaFe alloy was found at $358 \mathrm{~K}$, while the forward transformation in this printed alloy powder appears at $325 \mathrm{~K}$ and the reverse at $331 \mathrm{~K}$. The hysteresis worked out from the temperature difference was then $6 \mathrm{~K}$. For illustration of the magnetic response, we have put together the magnetization measured at $5 \mathrm{~K}$ under $2 \mathrm{~T}$ for the as milled, milled and annealed Ni-Mn-Ga powders, and both the Ni-Mn-Ga and Ni-Mn-Ga-Fe printed alloys. The magnetization of the two latter alloys located in between the as milled $\left(2.3 \mathrm{Am}^{2} / \mathrm{kg}\right)$ and milled and annealed $\left(73 \mathrm{Am}^{2} / \mathrm{kg}\right.$ ) NiMnGa powders and assumed the value of $34 \mathrm{Am}^{2} / \mathrm{kg}$ in the case of the Ni-Mn-Ga and $20 \mathrm{Am}^{2} / \mathrm{kg}$ in the case of the Ni-Mn-Ga-Fe alloy (Figure 11b). The remnant magnetization in both 3D printed alloys was at the similar level of 1.25 and $1.33 \mathrm{Am}^{2} / \mathrm{kg}$, whereas the coercivity was $588 \mathrm{Oe}$ and $1198 \mathrm{Oe}$ for the Ni-Mn-Ga and $\mathrm{Ni}-\mathrm{Mn}-\mathrm{Ga}-\mathrm{Fe}$ alloys, respectively.
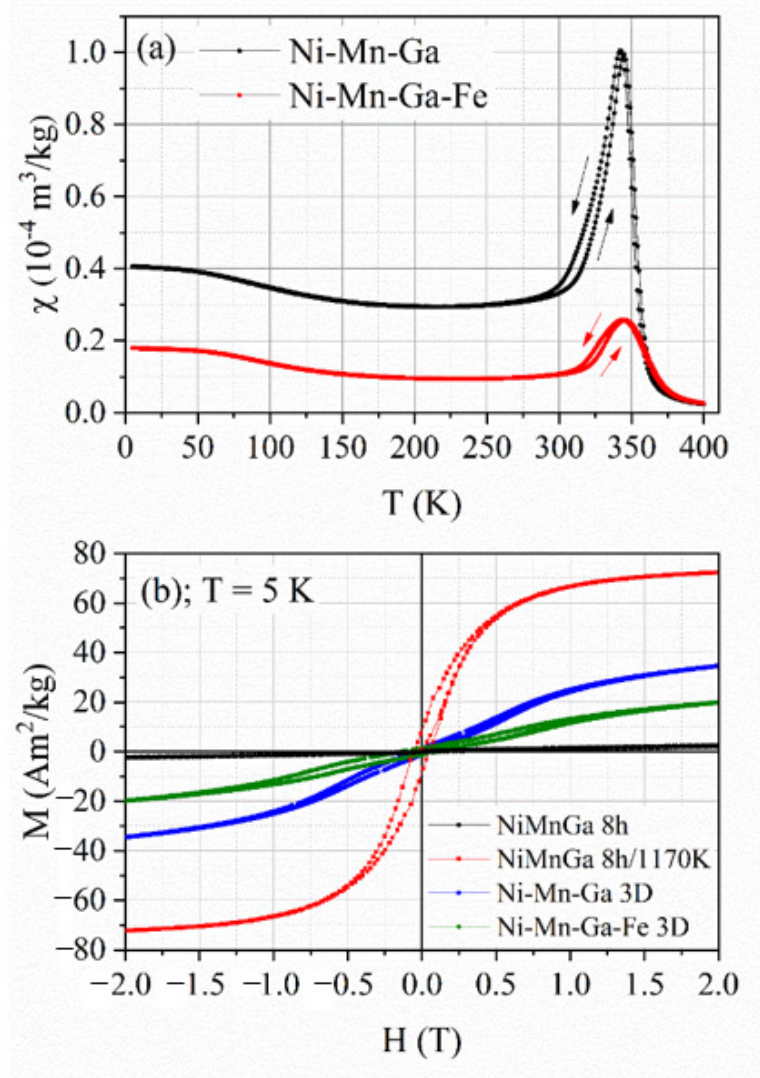

Figure 11. Magnetic susceptibility vs. temperature (a) and magnetic field dependence of magnetization (b) in as milled, milled and annealed and selected laser melted Ni-Mn-Ga and Ni-Mn-Ga-Fe powders. 
Overall, it was well demonstrated that milling deteriorates the functional performance of Ni-Mn-Ga base alloys. This was largely due to significant internal strains and disordering, which can stabilize the martensite phase or inhibit the transformation. Subsequent annealing restores the crystal structure, promotes ordering, and relieves internal strains, which then promotes the martensite transformation. This was also well evidenced form thermomagnetic measurements sensitive in general to the average Mn-Mn interatomic spacing, which was modified by mechanical milling. Interestingly from the same microstructural observations as well as magnetization measurements, it turns out that selected laser melting process applied to Ni-Mn-Ga and Ni-Mn-Ga-Fe as milled powders does not allow for full recovery of their functionality although it permits for compositional homogeneity. It further restores their ability to undergo a martensitic transformation in the ferromagnetic state, but in order to harness full functional performance, an additional heat treatment is necessary for improving their magnetic and overall response.

\section{Summary}

Ni-Mn-Ga and Ni-Mn-Ga-Fe were produced by selected laser melting from powdered as melt spun precursors. The resulting materials have a uniform chemical composition and are capable of martensitic transformation. At room temperature, both alloys display typical plate-like martensitic microstructure with an average plate thickness of $150 \mathrm{~nm}$. The subplate microstructure shows more complexity resulting from the self-accommodation process of martensite. Apart from martensite plates, the microstructure contains high density of stacking faults and dislocations. The martensite phase is found with dominating $10 \mathrm{M}$ and $14 \mathrm{M}$ modulated structure for $\mathrm{NiMnGa}$ and NiMnGaFe as laser melted samples, respectively, and they coexist with the parent $\mathrm{L} 2{ }_{1}$ and NM phase. From the magnetic susceptibility and magnetization measurement, it turns out that the ternary Ni-Mn-Ga shows a stronger magnetic response than the quaternary Ni-Mn-Ga-Fe, and both alloys undergo a martensitic transformation in the ferromagnetic state. Additional heat treatment is necessary for improving magnetization of the as printed alloys.

Author Contributions: Author Contributions: P.C., W.M., contributed primarily to writing the original draft and compiled the manuscript and the data collection; P.C., W.M., R.C., A.W., reviewing and editing, W.M. supervision; Ł.Ż., B.M., R.W., 3D printing—design and parameters optimization; W.M., R.C., A.W., M.K., project administration research and data collection. All authors have read and agreed to the published version of the manuscript.

Funding: National Centre for Research and Development (NCBiR) of Poland, grant number TECHMATSTRATEG 2/410941/4/NCBR/2019.

Institutional Review Board Statement: Not applicable.

Informed Consent Statement: Not applicable.

Data Availability Statement: The data presented in this study are available on request from the corresponding author.

Acknowledgments: National Centre for Research and Development (NCBiR) of Poland is acknowledged for funding (TECHMATSTRATEG 2/410941/4/NCBR/2019).

Conflicts of Interest: The authors declare no conflict of interest.

\section{References}

1. Pons, J.; Cesari, E.; Segui, C.; Masdeu, F.; Santamarta, R. Ferromagnetic shape memory alloys: Alternatives to Ni-Mn-Ga. Mater. Sci. Eng. 2008, 481, 57-65. [CrossRef]

2. Sozinov, A.; Musiienko, D.; Saren, A.; Vertat, P.; Straka, L.; Heczko, O.; Zeleny, M.; Chulist, R.; Ulakko, K. Highly mobile twin boundaries in seven-layer modulated Ni-Mn-Ga-Fe martensite. Scripta Mater. 2020, 178, 62-66. [CrossRef]

3. Chmielus, M.; Zhang, X.X.; Witherspoon, C.; Dunand, D.C.; Mullner, P. Giant magnetic-field-induced strains in polycrystalline Ni-Mn-Ga foams. Nat. Mater. 2009, 8, 863-866. [CrossRef] 
4. Laitinen, V.; Merabtene, M.; Stevens, E.; Chmielus, M.; Van Humbeeck, J.; Ullakko, K. Additive Manufacturing from the Point of view of Materials Research. In Technical, Economic and Societal Effects of Manufacturing 4.0; Collan, M., Michelsen, K.E., Eds.; Palgrave Macmillan: Cham, Switzerland, 2020. [CrossRef]

5. Mostafaei, A.; Kimes, K.A.; Stevens, E.L.; Toman, J.; Krimer, Y.L.; Ullakko, K.; Chmielus, M. Microstructural evolution and magnetic properties of binder jet additive manufactured Ni-Mn-Ga magnetic shape memory alloy foam. Acta Mater. 2017, 131, 482-490. [CrossRef]

6. Caputo, M.; Solomon, C.V. Microstructure and Chemical Composition Analysis of Additive Manufactured Ni-Mn-Ga Parts Sintered in Different Conditions. Microsc. Microanal. 2017, 23, 2078-2079. [CrossRef]

7. Caputo, M.; Solomon, C. A facile method for producing porous parts with complex geometries from ferromagnetic Ni-Mn-Ga shape memory alloys. Mater. Lett. 2017, 200, 87-89. [CrossRef]

8. Caputo, M.P.; Berkowitz, A.E.; Armstrong, A.; Müllner, P.; Solomon, C.V. 4D printing of net shape parts made from Ni-Mn-Ga magnetic shape-memory alloys. Addit. Manuf. 2018, 21, 579-588. [CrossRef]

9. Mostafaei, A.; De Vecchis, P.R.; Stevens, E.L.; Chmielus, M. Sintering regimes and resulting microstructure and properties of binder jet 3D printed Ni-Mn-Ga magnetic shape memory alloys. Acta Mater. 2018, 154, 355-364. [CrossRef]

10. Caputo, M.P.; Waryoba, D.R.; Solomon, C.V. Sintering effects on additive manufactured Ni-Mn-Ga shape memory alloys: A microstructure and thermal analysis. J. Mater. Sci. 2020, 55, 5311-5321. [CrossRef]

11. Stevens, E.; Kimes, K.; Salazar, D.; Mostafaei, A.; Rodriguez, R.; Acierno, A.; Lázpita, P.; Chernenko, V.; Chmielus, M. Mastering a $1.2 \mathrm{~K}$ hysteresis for martensitic para-ferromagnetic partial transformation in Ni-Mn(Cu)-Ga magnetocaloric material via binder jet 3D printing. Addit. Manuf. 2021, 37, 101560. [CrossRef]

12. Toman, J.; Müllner, P.; Chmielus, M. Properties of as-deposited and heat-treated Ni-Mn-Ga magnetic shape memory alloy processed by directed energy deposition. J. Alloys Compd. 2018, 752, 455-463. [CrossRef]

13. Stevens, E.; Toman, J.; Kimes, K.; Chernenko, V.; Wojcik, A.; Maziarz, W.; Chmielus, M. Microstructural Evaluation of Magnetocaloric Ni-Co-Mn-Sn Produced by Directed Energy Deposition. Microsc. Microanal. 2016, 22, 1774-1775. [CrossRef]

14. Stevens, E.; Kimes, K.; Chernenko, V.; Lazpita, P.; Wojcik, A.; Maziarz, W.; Chmielus, M. Direct Laser Deposition and Homogenization of Ni-Co-Mn-Sn Magnetocaloric Material. Microsc. Microanal. 2018, 24, 956-957. [CrossRef]

15. Ullakko, K.; Laitinen, V.; Saren, A.; Sozinov, A.; Musiienko, D.; Chmielus, M.; Salminen, A. Ni-Mn-Ga Actuating Elements Man-Ufactured using 3D Printing. In Proceedings of the 11th European Symposium on Martensitic Transformations, Metz, France, 27-31 August 2018.

16. Laitinen, V.; Salminen, A.; Ullakko, K. First investigation on processing parameters for laser powder bed fusion of Ni-Mn-Ga magnetic shape memory alloy. J. Laser Appl. 2019, 31, 022303. [CrossRef]

17. Nilsén, F.; Ituarte, I.F.; Salmi, M.; Partanen, J.; Hannula, S.-P. Effect of process parameters on non-modulated Ni-Mn-Ga alloy manufactured using powder bed fusion. Addit. Manuf. 2019, 28, 464-474. [CrossRef]

18. Laitinen, V.; Sozinov, A.; Saren, A.; Salminen, A.; Ullakko, K. Laser based 4D printing of Ni-Mn-Ga MSM alloy. In Proceedings of the 6th International Conference on Ferromagnetic Shape Memory Alloys: Book of Abstracts, Prague, Czech Republic, 2-7 June 2019; pp. 156-157, ISBN 978-80-905962-9-0.

19. Laitinen, V.; Sozinov, A.; Saren, A.; Chmielus, M.; Ullakko, K. Characterization of as-built and heat-treated Ni-Mn-Ga magnetic shape memory alloy manufactured via laser powder bed fusion. Addit. Manuf. 2021, 39, 101854. [CrossRef]

20. Stevens, E.L.; Kimes, K.A.; Chernenko, V.A.; Lázpita, P.; Wojcik, A.; Maziarz, W.; Toman, J.; Chmielus, M. Effect of Homogenization on the Microstructure and Magnetic Properties of Direct Laser-Deposited Magnetocaloric Ni43Co7Mn39Sn11. J. Manuf. Sci. Eng. 2020, 142, 1-26. [CrossRef]

21. Taylor, S.L.; Shah, R.N.; Dunand, D.C. Ni-Mn-Ga micro-trusses via sintering of 3D-printed inks containing elemental powders. Acta Mater. 2018, 143, 20-29. [CrossRef]

22. Taylor, S.L.; Shah, R.N.; Dunand, D.C. Microstructure and porosity evolution during sintering of Ni-Mn-Ga wires printed from inks containing elemental powders. Intermetallics 2019, 104, 113-123. [CrossRef]

23. Caputo, M.; Solomon, C.V.; Nguyen, P.-K.; Berkowitz, A.E. Electron Microscopy Investigation of Binder Saturation and Microstructural Defects in Functional Parts Made by Additive Manufacturing. Microsc. Microanal. 2016, 22, 1770-1771. [CrossRef]

24. Solomon, V.C.; Smith, D.J.; Tang, Y.-J.; Berkowtiz, A.E. Microstructural characterization of Ni-Mn-Ga ferromagnetic shape memory alloy powders. J. Appl. Phys. 2004, 95, 6954. [CrossRef]

25. Wang, Y.D.; Ren, Y.; Nie, Z.; Liu, D.M.; Zuo, L.; Choo, H.; Li, H.; Liaw, P.K.; Yan, J.Q.; McQueeney, R.; et al. Structural transition of ferromagnetic Ni2MnGa nanoparticles. J. Appl. Phys. 2007, 101, 063530. [CrossRef]

26. Czaja, P.; Chulist, R.; Wójcik, A.; Kowalczyk, M.; Zackiewicz, P.; Szewczyk, A.; Schell, N.; Maziarz, W. Suppression and Recovery of Martensitic Transformation and Magnetism in Mechanically and Thermally Treated Magnetic Shape-Memory Ni-Mn-Ga Melt-Spun Ribbons. Adv. Eng. Mater. 2021, 2100075. [CrossRef]

27. Chulist, R.; Straka, L.; Seiner, H.; Sozinov, A.; Schell, N.; Tokarski, T. Branching of (110) twin boundaries in five-layered Ni-Mn-Ga bent single crystals. Mater. Des. 2019, 171, 107703. [CrossRef]

28. Chulist, R.; Czaja, P. On the role of atomic shuffling in the $4 \mathrm{O}, 4 \mathrm{M}$ and $8 \mathrm{M}$ martensite structures in Ni-Mn-Sn single crystal. Scr. Mater. 2020, 189, 106-111. [CrossRef]

29. Chulist, R.; Nalepka, K.; Sozinov, A. Hierarchical twin microstructure in modulated 10M Ni-Mn-Ga single crystals. An analysis including shuffling of atomic layers. Int. J. Plast. 2020, 126, 102628. [CrossRef] 